16. Справочник по гидрохимии / под ред. докт. геол.-минер. наук А.М. Никанорова. Л.: Гидрометеоиздат, 1989. $391 \mathrm{c.}$

17. Собакина И.Г. Современное состояние зоопланктона озер Лено-Амгинского междуречья // Экология России: на пути к инновациям: межвуз. сб. науч. тр. Вып. 7. Астрахань: Издательство Нижневолжского экоцентра, 2013. С. 113-116.

18. Собакина И.Г. К изучению зоопланктона озер долины Туймаада // Экология России: на пути к инновациям: межвуз. сб. науч. тр. Вып. 7. Астрахань: Изд-во Нижневолжского экоцентра, 2013. С. 106-112.
19. Собакина И.Г., Венедиктов С.Ю., Климовский А.И., Соколова В.А. К изучению современного состояния условий обитания гидробионтов в озере Белое // География и краеведение в Якутии: сб. матлов II респуб. науч.-практ. конф. Якутск: Информационно-технологический отдел управления информатизации и инноваций СВФУ, 2011. С. 223-227.

20. Трофимова Т.П., Жирков И.И. Экологическое состояние уникального озера Ниджили // География и туризм. № 10. Киев: Альтерпресс, 2010. С. 185191.

\title{
ASSESSMENT OF SEISMIC VIBRATORY IMPACT ON EXPERIMENTAL LAKES ECOSYSTEMS
}

(C) 2018

\author{
Zhirkov Innokenti Innokentyevich, candidate of geographical sciences, \\ leading researcher of Limnology Laboratory \\ Tyaptirgyanov Matvei Matveevich, doctor of biological sciences, \\ associate professor of Botany and Zoology Department
}

Trofimova Tamara Petrovna, head of Limnology Laboratory Sobakina Irina Grigoryevna, research engineer of Applied Zoology Laboratory Zhirkov Konstantin Innokentyevich, leading engineer of Limnology Laboratory M.K. Ammosov North-Eastern Federal University (Yakutsk, Russian Federation)

Abstract. The paper deals with the assessment of seismic vibratory impact on experimental lakes ecosystems Changes of chemical and zooplanktonic composition of experimental lakes before vibration works were studied. Crucian carps were used for the assessment of vibratory impact. Hydrochemical researches included definition of organoleptic indicators, dissolved gases, biogenous elements, organic substance and the main ions, polluting substances and metals. The chemical analysis is carried out by standard hydrochemistry techniques. 18 samples on quantitative and qualitative structure of a zooplankton were collected and processed. Zooplankton organisms definition was carried out by means of widely used determinants. For icthyological researches fish caught in Nidzhili Lake was used. The bioanalysis was carried out by standard ichthyology techniques. The conducted pilot studies have shown that such quantitative and qualitative water condition changes and such vibratory impact on zooplanktonic organisms and crucians condition which we consider reaching catastrophic influences. If to take into account intensity and efficiency of fish, zooplanktonic and bentosny organisms' restoration in the studied lakes, it is possible to consider that there are no cardinal changes in hydrobionts and fish fauna as a result of vibratory impact. It is also possible to assume that the essential part of such changes remains out of attention and opportunities of modern monitoring.

Keywords: experiment; vibration; seismic exploration; harmful effects; fishery lake; winter mode; hydrochemistry; organoleptic properties; biogenous, organic and pollutants; zooplanktonic structure; number; biomass; Carassius auratus; Carassius carassius; kriolitozona; Western Yakutia.

\section{РАДИОЭКОЛОГИЧЕСКАЯ ОБСТАНОВКА НА ТЕРРИТОРИИ ДЕЯТЕЛЬНОСТИ ПРИВОЛЖСКОГО УПРАВЛЕНИЯ ПО ГИДРОМЕТЕОРОЛОГИИ И МОНИТОРИНГУ ОКРУЖАЮЩЕЙ СРЕДЫ В 2016 ГОДУ} (C) 2018

Залыбина Юлия Николаевна, аспирант кафедры экологии и охраны окружающей среды Григорьев Василий Семенович, доктор биологических наук, профессор, заведующий кафедрой экологии и охраны окружающей среды

Склюев Валерий Витальевич, кандидат биологических наук, декан химико-биологического факультета Самарская государственная областная академия (Наяновой) (2. Самара, Российская Федераџия)

Аннотащия. Крайне актуальным представляется вопрос о качестве окружающей среды, в том числе с учетом радиоэкологической обстановки. В рамках развития местного сельского хозяйства необходимо учитывать различные радиационные параметры, определяющие современную радиационную обстановку. В частности, необходим регулярный радиоэкологический мониторинг загрязнения окружающей среды Самарской области и сопредельных территорий по основным видам радиометрических наблюдений. В публикации делается акцент на достоверном и оперативном обнаружении радиоактивного загрязнения, на оценке радиационной обстановки с помощью радиоэкологического контроля компонентов природной среды. В статье на основании результатов мониторинга ФГБУ «Приволжское УГМС» проведена оценка радиационной обстановки в населенных пунктах Самарской, Саратовской, Оренбургской, Пензенской и Ульяновской областей. Приводятся значения концентрации суммарной $\beta$-активности аэрозолей приземного слоя атмосферы, данные сред- 
негодовых величин МЭД по Самарской и сопредельным областям. По данным радиоэкологического мониторинга показан уровень суммарной $\beta$-активности радиоактивных выпадений из атмосферы. Максимальные значения концентрации суммарной $\beta$-активности аэрозолей приземного слоя атмосферы были зафиксированы в летний период, что обусловлено вторичным ветровым подъемом пыли с загрязненных территорий. Показано, что среднегодовая величина суммарной $\beta$-активности аэрозолей по результатам исследований находится в пределах нормы. Также в работе содержатся выводы о степени опасности загрязнения приземного слоя атмосферы техногенными радионуклидами.

Ключевые слова: мощность амбиентного эквивалента дозы $\gamma$-излучения (МЭД); радиоэкологический мониторинг; суммарная $\beta$-активность; среднегодовая величина МЭД; радиационная обстановка; радиометрические наблюдения; радионуклиды; контроль загрязнения; радиационная безопасность.

\section{Актуальность исследования}

Защита окружающей среды давно стала глобальной проблемой, занимающей одно из центральных мест в обеспечении устойчивого развития человеческого общества $[1 ; 2]$. Вопрос о качестве окружающей среды подразумевает создание системы, способной как определять источники и факторы техногенного воздействия на население и состояние окружающей среды, подверженные такому воздействию, так и оценивать степень этого воздействия [3; 4]. С развитием местного сельского хозяйства становится актуальным учет радиоэкологической обстановки на территориях сельхозугодий [5; 6]. Поэтому необходимо проведение экологического мониторинга как системы регулярных, длительных наблюдений в пространстве и во времени, дающей информацию о состоянии окружающей среды с целью оценки прошлого, настоящего и прогнозов на будущее параметров окружающей среды, имеющих значение для человека [7-9]. Непосредственная связь методологии экологических исследований с эмпирическими данными радиационного мониторинга в зонах воздействия промышленных предприятий делает радиоэкологический мониторинг крайне актуальным [5; 10].

Кроме того, правительством РФ на ближайшие 10-15 лет поставлены задачи совершенствования и развития радиоэкологического мониторинга с целью повышения оперативности и полноты представления информации об уровнях радиоактивного загрязнения окружающей среды и уровнях воздействия на среду обитания человека [5; 11].

Целью исследования является проведение анализа результатов радиоэкологического мониторинга загрязнения окружающей среды Самарской области и сопредельных территорий по основным видам радиометрических наблюдений для описания радиационной обстановки на территории деятельности ФГБУ «Приволжское УГМС» в 2016 году.

Развитие и широкое использование ядерной энергии в различных сферах человеческой деятельности связано с поступлением в биосферу огромного количества радионуклидов и участие их во многих биологических процессах, что формирует дополнительное к природному фону облучение живых организмов [6; 7]. Рассеянные в земной коре природные радионуклиды естественного происхождения, такие как радий, торий и продукты их радиоактивного распада, содержатся в воздухе, почве, растительности, воде, в строительных и промышленных материалах, зданиях, в кормах и пищевых продуктах [12; 13]. Радиоэкологическая обстановка на территории России складывается за счет естественного радиационного фона, радиоактивных выпадений после радиационных аварий и инцидентов на предприятиях ядерно- топливного производства, глобальных выпадений, радиоактивных выбросов в атмосферу и сбросов в водные системы нормированного количества радиоактивных веществ [8; 14]. Необходимо учитывать проявление вторичных эффектов загрязнения, связанных с выносом продуктов деления на поверхность земли талыми и ливневыми водами, ветровым переносом, миграцией радионуклидов по пищевым цепочкам [15].

Контроль загрязнения окружающей среды техногенными радионуклидами является неотъемлемой частью системы обеспечения радиационной безопасности населения и охраны окружающей среды, которая подразумевает создание современных систем радиоэкологического мониторинга [14].

Достоверное и оперативное обнаружение радиоактивного загрязнения, оценка степени распространения радиоактивного заражения по всей территории региона является одной из важнейших задач радиоэкологического мониторинга [1]. После ряда крупных аварий на радиационно-опасных объектах разработка таких систем стала необходимой частью планов национальной безопасности многих стран $[12 ; 13]$.

\section{Материалы и методы исследования}

Оценка радиационной обстановки на территории РФ осуществляется с помощью радиоэкологического контроля компонентов природной среды (измерение мощности амбиентного эквивалента дозы $\gamma$-излучения (МЭД), расчет суммарной- $\beta$ активности радиоактивных выпадений и аэрозолей) проводится на стационарных пунктах наблюдения (гидрометеорологических станциях и постах), входящих в систему радиационного мониторинга (СРМ) Росгидромета. Федеральное государственное бюджетное учреждение «Приволжское управление по гидрометеорологии и мониторингу окружающей среды» (далее - ФГБУ «Приволжское УГМС»), которое входит в состав СРМ Росгидромета, осуществляет контроль радиоактивного состояния окружающей среды на территориях Самарской, Саратовской, Оренбургской, Пензенской и Ульяновской областей.

Ежедневные измерения уровня МЭД $\gamma$-излучения проводятся на специально оборудованных пунктах наблюдения, которые размещаются на территориях гидрометеорологических станций и постах. Для измерения МЭД на местности применяются дозиметры и дозиметры-радиометры различных типов, например дозиметры ДКГ-07Д «ДРОЗД», ДКГ-03Д «ГРАЧ», ДКГ-02У «АРБИТР», ДБГ-06Т и др. [16; 17].

Размеры участка для измерения МЭД с поверхности почвенно-растительного покрова составляют $5 \times 5$ м. Непосредственно место для измерений в цен- 
тре участка размером $1 \times 1$ м должно быть ровным, на нем не должны скапливаться талые или дождевые воды. В середине выбранного места (участка) устанавливается столик для дозиметра и журнала записи наблюдений, высота столешницы над землей 1 м.

Пробы атмосферных радиоактивных выпадений отбираются ежедневно с помощью горизонтального планшета, который представляет собой квадратный столик с прижимными уголками сверху. Горизонтальный планшет устанавливается на метеоплощадке вдали от метеорологических приборов и установок. Приемная часть горизонтального планшета фиксируется на высоте 1 м от поверхности земли или снега. Для стандартизации условий отбора проб радиоактивных выпадений из атмосферы на горизонтальный планшет и сравнимости данных наблюдений используется только отбеленная медицинская марля. Применение других сортов марли не допускается. Смена марли на планшете производится один раз в сутки (суточная экспозиция).

Пробы радиоактивных выпадений, снятые с горизонтального планшета, необходимо сконцентрировать в минимальном объеме, чтобы увеличить эффективность регистрации отобранных радиоактивных продуктов. Поэтому пробы озоляются в муфельной печи при температуре $450^{\circ} \mathrm{C}$, т.к. при более высокой температуре заметная возгонка цезия и рутения. Отбор проб атмосферных радиоактивных аэрозолей из приземного слоя атмосферы проводится с помощью воздушно-фильтрующей установки (ВФУ) «Тайфун», принцип действия которой основан на методе фильтрации воздуха через тонковолокнистый фильтр (ткань Петрянова) с одновременным измерением объемного расхода воздуха.

\section{Результаты и их обсуждение}

По данным радиоэкологического мониторинга ФГБУ «Приволжское УГМС», мощность амбиентного эквивалента дозы $\gamma$-излучения (МЭД - это отношение приращения амбиентного эквивалента дозы за интервал времени к величине этого интервала; Зв/ч, м3в/ч, мкЗв/ч) в течение 2016 года находилась в пределах естественного радиационного фона (рис. 1).

Как видно из рис. 1, на территории Самарской области максимальное значение МЭД зарегистрировано в июне на ОГМС Самара и составляло 0,17 мкЗв/ч. Среднегодовая величина МЭД по Самарской области не превышала 0,10 мкЗв/ч. На МC Айдырля Оренбургской области максимальная величина МЭД $\gamma$-излучения зафиксирована в мае на уровне 0,18 мкЗв/ч, среднегодовая составляла 0,11 мкЗв/ч. На территории Ульяновской области максимальное значение МЭД не превышало 0,18 мкЗв/ч и было отмечено на нескольких станциях: МС Канадей (в апреле), МС Сенгилей (в сентябре) и на МС Сурское (в декабре). Среднегодовая величина МЭД по Ульяновской области не превышала 0,11 мкЗв/ч. Максимальная величина МЭД $\gamma$-излучения на территории Пензенской области зафиксирована на ЦГМС Пенза в июне и октябре на уровне 0,19 мкЗв/ч, среднегодовое значение составляло 0,12 мкЗв/ч. На территории Саратовской области максимальное значение МЭД зарегистрировано в апреле на МС Балаково и составляло 0,23 мкЗв/ч. Среднегодовая величина МЭД по Саратовской области не превышала 0,12 мкЗв/ч.

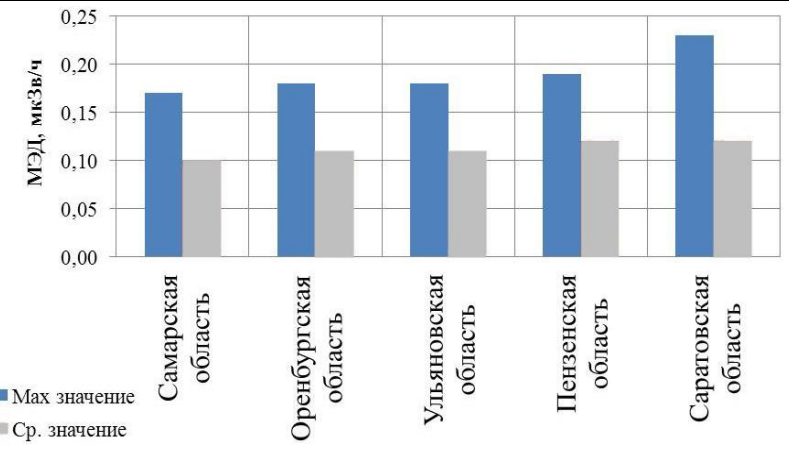

Рисунок 1 - Значение мощности амбиентного эквивалента дозы (МЭД) ү-излучения на территории деятельности ФГБУ «Приволжское УГМС» в 2016 году

По результатам радиоэкологического мониторинга концентрации суммарной $\beta$-активности радиоактивных аэрозолей в 2016 году не достигали критери-

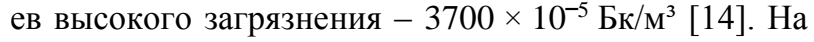
территории Пензенской области, в пункте наблюдения ЦГМС Пенза, максимальное значение зафиксировано в июле на уровне $22,1 \times 10^{-5} \mathrm{Б \kappa} / \mathrm{M}^{3}$, среднегодовая величина составляла $7,1 \times 10^{-5}$ Бк/м ${ }^{3}$ (рис. 2).

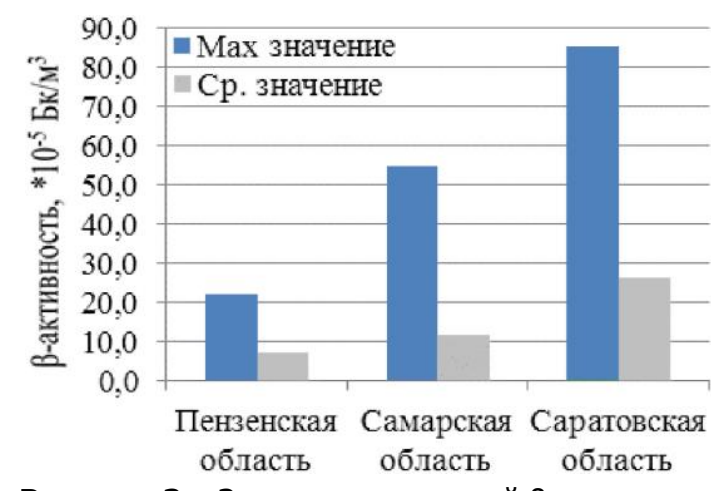

Рисунок 2 - Значение суммарной $\beta$-активности атмосферных радиоактивных аэрозолей в 2016 году, $\times 10^{-5} \mathrm{БK} / \mathrm{M}^{3}$

Максимальная концентрация суммарной $\beta$-активности в пункте наблюдения ОГМС Самара (Самарская область) обнаружена в августе на уровне

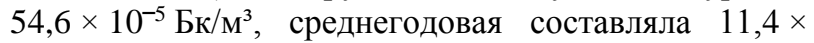
$\times 10^{-5}$ Бк/M $\mathrm{M}^{3}$ (рис. 2). В пункте наблюдения МС Балаково Саратовской области максимальное значение обнаружено в июле и не превышало $85,2 \times 10^{-5}$ Бк/ $\mathrm{M}^{3}$, среднегодовая величина зарегистрирована на уровне $26,2 \times 10^{-5}$ Бк/ $\mathrm{M}^{3}$ (рис. 2).

По данным радиоэкологического мониторинга значение суммарной $\beta$-активности радиоактивных выпадений из атмосферы в 2016 году не достигало критериев высокого загрязнения - 110 Бк $/ \mathrm{M}^{2}$ ·сутки [14]. Как видно на рис. 3, на территории Саратовской области концентрация суммарной $\beta$-активности зафиксирована в январе на МС Новоузенск и не пре-

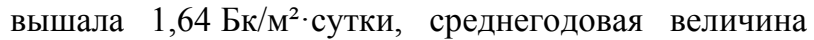
составляла 0,46 Бк/ $\mathrm{M}^{2} \cdot$ сутки. На МС Димитровград Ульяновской области максимальное значение суммарной $\beta$-активности обнаружено в мае на уровне 2,66 Бк/ $\mathrm{M}^{2} \cdot$ сутки, среднегодовое значение не превышало 0,49 Бк/м² сутки (рис. 3).

Максимальная концентрация суммарной $\beta$-активности радиоактивных выпадений на территории Самарской области зарегистрирована в декабре на ОГМС Самара на уровне 11,90 Бк/ $\mathrm{M}^{2} \cdot$ сутки, среднегодовая составляла 1,38 Бк/м² сутки (рис. 3). На тер- 
ритории Оренбургской области максимальное значение суммарной $\beta$-активности обнаружено на МС Бу-

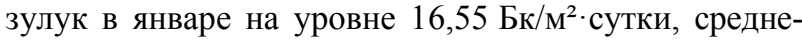
годовая концентрация не превышала 1,33 Бк/ $\mathrm{M}^{2} \cdot$ сутки (рис. 3).

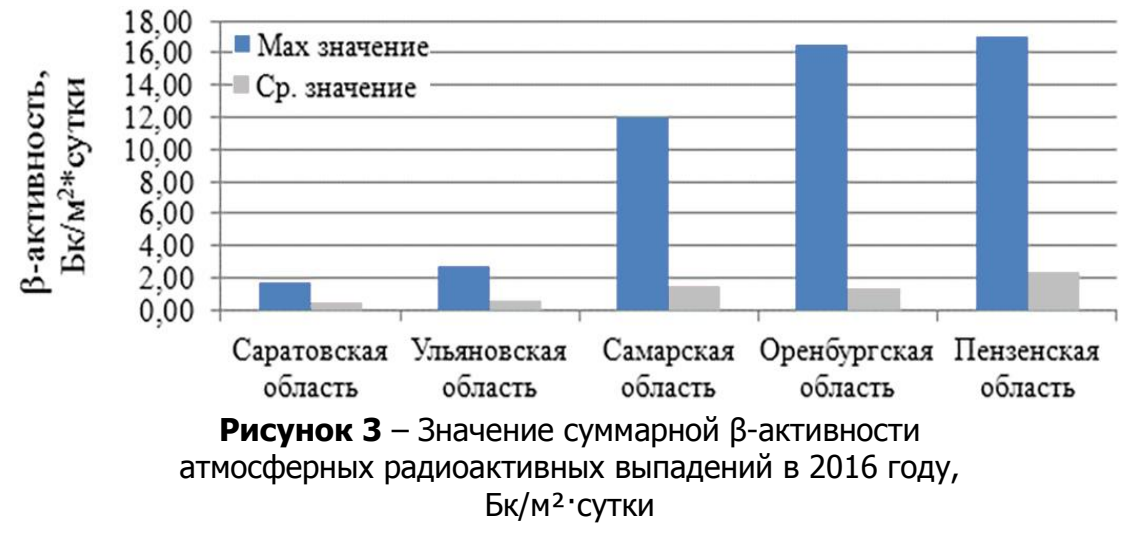

\section{Выводы}

Максимальные значения концентрации суммарной $\beta$-активности аэрозолей приземного слоя атмосферы зафиксированы в летний период, что обусловлено вторичным ветровым подъемом пыли с загрязненных территорий. Среднегодовая величина суммарной $\beta$-активности аэрозолей находится в пределах нормы [14].

Максимальная концентрация суммарной $\beta$-активности выпадений зафиксировано зимой и весной, что связано с деятельностью ТЭЦ в отопительный период.

Деятельность Балаковской АЭС и Димитровградского НИИАР не оказывает значительного влияния на радиационную обстановку.

По результатам радиоэкологического мониторинга радиационная обстановка на территории деятельности ФГБУ «Приволжское УГМС» в 2016 году была стабильной. Зарегистрированные максимальные значения не являются случаями высокого или экстремально высокого загрязнения.

Уровни загрязнения приземного слоя атмосферы техногенными радионуклидами ниже установленных в НРБ-99/2009 нормативов и не представляют опасности для здоровья населения [14].

\section{Список литературы:}

1. Семенихина М.Е. Некоторые аспекты радиоэкологического мониторинга объектов окружающей природной среды в районе размещения КАЭС // Вестник МГТУ. 2006. Т. 9, № 5. С. 843-846.

2. Черняго Б.П., Непомнящих А.И., Медведев В.И. Современная радиационная обстановка в центральной экологической зоне Байкальской природной территории // Геология и геофизика. 2012. Т. 53, № 9. C. $1206-1218$.

3. Актуальные проблемы ограничения облучения населения от природных источников ионизирующего излучения: Радон-2000: мат-лы науч.-практ. конф., 18-20 апр. 2000 г., г. Пущино. М., 2000. 185 с.

4. Посохов Н.Н., Азаров С.Г., Прошляков М.Ю. Проблемы развития систем мониторинга потенциально опасных объектов и пути их решения // Мониторинг. Наука и безопасность. 2011. № 1. С. 8-11.

5. Булдаков Л.А. Радиоактивные вещества и человек. М.: Энергоатомиздат, 1990. 160 с.
Максимальное значение суммарной $\beta$-активности на территории Пензенской области (ЦГМС Пенза) зафиксировано в марте на уровне 17,02 Бк/м ${ }^{2}$ ссутки, среднегодовое значение составляло 2,28 Бк/ $\mathrm{M}^{2} \cdot$ сутки (см. рис. 3).
6. Бекман И.Н., Хасков М.А., Пасека В.И., Панаркина Л.Е., Рязанцев Г.Б. Вариации радиационного фона и климатических параметров в северной части Азовского моря // Экологические системы и приборы. 2005. № 2. С. 20-28.

7. Алукер Н.Л., Крысанова О.Л., Сорокина Н.В. Дозиметрический мониторинг населения Кузбасса с помощью термолюминесцентных детекторов ТЛД-К // Радиоактивность и радиоактивные элементы в среде обитания человека: мат-лы II междунар. конф., Томск, 18-22 октября 2004 г. Томск: Изд-во «Тандем-Арт», 2004. С. 34-36.

8. Алукер Н.Л., Сорокина Н.В., Суздальцева Я.М. Исследование поглощенных доз радиации в пробах почво-грунтов и воде за счет содержавшихся в них радионуклидов при помощи термолюминесцентных детекторов // Радиоактивность и радиоактивные элементы в среде обитания человека: мат-лы IV междунар. конф. (Томск, 4-8 июня 2013 г.). Томск: Изд-во Томского политехнического университета, 2013. C. $42-45$.

9. Быстраков Ю.И., Колосов А.В. Экономика и экология. М.: Агропромиздат, 1988. 204 с.

10. Василенко О.И. Радиационная экология. М.: Медицина, 2004. 216 с.

11. Радиационная гигиена. 2016. Т. 9, № 4.100 с.

12. Вариации содержания Ве-7 в приземном слое атмосферы на средних широтах / Т.Б. Петрова, П.С. Микляев, В.К. Власов, А.М. Афиногенов, О.В. Кирюхин // Вестник Московского Университета. Серия 2. Химия. 2009. № 5. С. 49-51.

13. Соловьев Л.Н. Стратосферный сток Ве-7 // Известия СПбГЭТУ «ЛЭТИ». 2016. № 6. С. 91-95.

14. СанПиН 2.6.1.2523-09 Санитарные правила и нормативы. Нормы радиационной безопасности (НРБ-99/2009).

15. Габлин В.А. О классификации дисперсных грунтов в радиоэкологических исследованиях // АНРИ. 1999. № 4. С. 27-30.

16. ГОСТ Р 52931-2008. Приборы контроля и регулирования технологических процессов. Общие технические условия. М.: Стандартинформ, 2009.

17. Нурлыбаев К. Государственный реестр средств измерений РФ: приборы радиационного контроля. Ч. 2. Носимые радиометры-дозиметры // АНРИ. 2007. № 4 (51). С. $2-9$. 


\title{
RADIOECOLOGICAL SITUATION ON THE TERRITORY OF THE VOLGA REGION DEPARTMENT OF HYDROMETEOROLOGY AND ENVIRONMENTAL MONITORING IN 2016
}

(C) 2018

\author{
Zalybina Yuliya Nikolaevna, postgraduate student of Ecology and Environmental Protection Department \\ Grigoriev Vasily Semenovich, doctor of biological sciences, professor, \\ head of Ecology and Environmental Protection Department \\ Sklyuev Valeriy Vitalyevich, candidate of biological sciences, head of Chemistry and Biology Department \\ Samara State Regional Academy (Nayanova) (Samara, Russian Federation)
}

Abstract. The environment quality is an extremely relevant question, including taking into account radioecological situation. The development of local agriculture should take into account various radiation parameters that determine the current radiation situation. In particular, it is necessary to do regular radioecological monitoring of environmental pollution of the Samara Region and adjacent territories on the main types of radiometric observations. The paper focuses on the reliable and rapid detection of radioactive contamination, assessment of the radiation situation with the help of radio-ecological control of natural environment components. In the paper on the basis of the Volga Region Department of Hydrometeorology and Environmental Monitoring data the authors assess the radiation situation in the settlements of Samara, Saratov, Orenburg, Penza and Ulyanovsk Regions. The paper contains values of aerosols $\beta$-activity concentration in the surface layer of the atmosphere as well as the data of the average annual values in Samara and adjacent regions. According to the data of radioecological monitoring the level of total $\beta$ activity of radioactive fallout from the atmosphere is shown. The maximum values of the total $\beta$-activity concentration of the atmospheric surface layer aerosols were recorded in summer, which is due to the secondary wind dust rise from the contaminated areas. It was shown that the average annual value of the total $\beta$-activity of aerosols according to the results of studies is within the normal limits. The paper also contains conclusions about the degree of danger of the atmosphere surface layer contamination by technogenic radionuclides.

Keywords: ambient dose equivalent dose of $\gamma$-radiation (EDR); radioecological monitoring; total $\beta$-activity; average value of dose rate; radiation environment; radiation monitoring; radionuclides; contamination control; radiation safety.

\section{СТРУКТУРА ОРНИТОКОМПЛЕКСОВ ТЕХНОГЕННО НАРУШЕННЫХ ТЕРРИТОРИЙ ЛЕВОБЕРЕЖНОЙ ЧАСТИ ЮЖНО-МИНУСИНСКОЙ КОТЛОВИНЫ}

(C) 2018

Злотникова Тамара Викторовна, кандидат биологических наук, доцент кафедры биологии Хакасский государственный университет им. Н.Ф. Катанова (2. Абакан, Российская Федераџия)

Аннотация. В данной статье рассматривается видовая и экологическая структура орнитологических комплексов на территориях карьерных выемок. Исследования проведены в левобережной части ЮжноМинусинской котловины. Круглогодично исследовали 6 карьеров, эпизодически - 4. Карьеры различного назначения (добыча песка, глины, щебня, складирование бытового мусора), возраста (от 1 года до 15 лет) и размеров (от 1 до 20 га). Выявлено 39 видов птиц, что составляет более 15\% от авифауны котловины. Наибольшим числом видов (по 4-6) представлены семейства Fringillidae, Corvidae, Sylviidae, Muscicapidae. Установлен характер пребывания видов на территории. Гнездящихся видов отмечено 19, посетителей - 20. Только в летний период встречается 25 видов, только в зимний период - 7 видов, ещё 7 видов отмечены на площадках как летом, так и зимой. Гнездятся преимущественно дендрофильные и петрофильные виды. На всех участках отмечено гнездование Passer montanus (L.) и Oenanthe oenanthe (L.), на большинстве - Riparia riparia (L.). Большинство видов синантропные. Показано, что видовое богатство птиц определяется, в первую очередь, структурой местообитания: наличие вертикальных обрывов грунта, каменных сооружений, деревьев, кустарников, травяного покрова, водоёмов. Определённое значение имеют также наличие пищевых отходов и характер окружающих биотопов.

Ключевые слова: Южно-Минусинская котловина; техногенный ландшафт; карьер; орнитокомплекс; экологические группы птиц; синантропные птицы; петрофильные птицы; дендрофильные птицы; гнездящиеся виды; виды-посетители; места гнездования; структура местообитания; Passer montanus; Oenanthe oenanthe; Riparia riparia.

\section{Введение}

Минусинские межгорные котловины расположены в северной части Алтае-Саянской горной области. Южно-Минусинская - самая южная из них. Меридионально котловину пересекает р. Енисей, разделяя её на правобережную (восточную) и левобережную (западную) части. Левобережная часть административно относится к Республике Хакасия.
Рельеф котловины преимущественно равнинный, средняя высота - 300-400 м над ур. м. Климат резко континентальный. На выровненных водоразделах представлены мелкодерновинные степи, на каменистых субстратах - каменистые степи. Ложбины и северные склоны занимают обеднённые варианты луговых степей, северные склоны сопок высотой 550600 м над ур. м. заняты остепнёнными (преимуще- 